\title{
Guideline for green design of water heater products
}

\author{
Jianfang Zong*, Dongfeng Gao, Jianwei Tian, Xin Zhang \\ China National Institute of Standardization, No.4 Zhichun Road, Haidian District, Beijing, 100191
}

\begin{abstract}
This paper investigates the overseas and domestic backgrounds for green design of water heater products, regulates the purposes and basic principles of eco-design of water heater products, and provides the eco-design requirements, eco-design procedure, major methods of eco-design, eco-design evaluation and improvement, and product information provision and sharing. This paper will provide the guiding targets for the water heater product manufacturer, standardize the enterprise behavior of water heater product, and lead the water heater product enterprise to implement the product green design, which is of great significance in promoting the transformation and upgrading of water heater product, enhancing the green manufacturing level and increasing the green product supply.
\end{abstract}

With the enhancement of domestic living standards, the application of water heater in the industrial and civil buildings has become increasingly popular, and the water heater has already become one of the major household energy-consuming equipment. The domestic water heater mainly includes four main classes, namely, the electric water heater, gas water heater, solar water heater and heat pump water heater developed in recent years, while its domestic sales were quickly increased from less than 8 million sets 10 years ago to the present 40 million plus sets. Therefore, the eco-design of water heater accords with the requirements of consumption upgrading, increases the supply of green products, and enables the consumer to select and use the green products, so as to ease the pressure on resources and energy, and reduce the adverse impacts upon the environment and human beings.

The green design of water heater product is also called "environmental conscious design", "eco-design" or "design for the environment". The green design of water heater products intends to optimize the environmental impact of water heater product and bring the environmental factors into the product design and development activity, so as to improve the environmental performance of water heater product within its life cycle. The eco-design is the activity which intends to systematically consider the impacts of selection, production, sales, use, recovery, processing and other links of raw materials upon resources and environment at the product design and development phases, as per the concept of whole life cycle, strive to minimize the resources consumption during the whole life cycle of the product, try to use less or not use raw materials containing toxic or harmful substances, and reduce the production and emission of pollutants, so as to realize the environmental protection. The eco-design is the significant measures to realize the pollution prevention. The pollution prevention is the fundamental method to change the development pattern of "treatment after pollution". As shown in the study, $80 \%$ resources consumption and environmental impact are subject to the product design phase. At the design phase, it is required to fully consider the existing technical conditions, raw materials guarantee and other factors, and optimize the solution against the resources and environmental problems at each link, which may maximize the resources conservation and reduce the environmental pollution from the source $[1,2]$.

The eco-design phase includes the determination of the design products and objectives, planning and organization, requirements analysis, preparation of design specification, product design and implementation design, completion of scheme design, general scheme design, systematic design, engineering design and other relevant documents. In design, it is required to consider the processing (reuse, recycling and disposal) requirements of the termination of product life span (end point), select the appropriate handling methods and estimate the costs. It is required to select and apply the product design tools compatible with the environment, such as the life cycle assessment (hereinafter referred to as "LCA"), so as to optimize the product design. Meanwhile, it is required to select the final disposal methods of products as per the principle of minimum environmental impact.

\section{OVERSEAS AND DOMESTIC BACKGROUNDS FOR GREEN DESIGN OF WATER HEATER PRODUCTS}

In 2009, the European Parliament and Council of the European Union published Establishing a Framework for the Setting of Eco-Design Requirements for Energy-Related Products (ERP Directive No. 2009/ 125 ( EC), including the relevant contents of water heater

\footnotetext{
* Corresponding author: zongjf@enis.gov.cn
} 
product directive. In 2009, China issued General Principle and Requirements of Eco-Design for Products (GB/T 24256-2009 [3]), regulating the general principle and requirements of eco-design for products. In 2015, China issued General Principles for Eco-Design Product Assessment (GB/T 32161-2015 [4]), regulating the principle and methods of eco-design products evaluation, and preparation methods of life cycle evaluation report. As per these two significant standards within the ecodesign field, and in combination with the present ecodesign development status of water heater industry in China, it is required to provide the detailed requirements upon the water heater products in accordance with General Principle and Requirements of Eco-Design for Products (GB/T 24256-2009), and ensure that the water heater product designed as per this standard conforms to the relevant eco-design requirements provided in General Principles for Eco-Design Product Assessment (GB/T 32161-2015).

At present, there are many theoretical studies and gradually increased standards, but there still lacks of the eco-design standards related to the water heater products with the vast quantity and broad influence. Besides, the development progress of China's eco-design products is much slower. The main reasons are as follows: many enterprises manufacture the OEM product, while the design technology is grasped by the foreign companies. Therefore, such enterprises are in no hurry to consider the eco-design researches, and do not have their own eco-design system. Meanwhile, many small and medium-sized enterprises lack of the research capacity in this regard, and it is hard for them to establish their own ecological product development system. Most of them are waiting for the national policy and the promotion and application of large-scale enterprises' technical research results. Some domestic enterprises with the research and product development capacity, still do not actually form the ecological product R\&D system of their own characteristics, and are especially deficient at the following aspects:

(1) They still do not establish the eco-design standards system. At present, the overseas enterprises have already evaluated the ecological properties from the perspective of environmental impacts of product life cycle, while the domestic enterprises still evaluate the eco-design products as per the single index, such as without CFC, energy saving, low noise, and etc. Therefore, it is still not the actually eco-design standards.

(2) China still lacks of the complete and systematic eco-design evaluation, examination and assessment system, and does not form the complete laws and regulations system, while the eco-design is still subject to the vigorous cultivation of the relevant departments.

(3) The product eco-design of overseas enterprises not only stays at the consciousness and concept level, but also establishes the detailed and operable methods and assessment and management fundamental platform. Meanwhile, it has already been pushed from the product design to the eco-design and management of the product chain. China still stays at the concept discussion level, and lacks of the controllable design indexes and operable systematic design methods, as well as the design basic data and design pattern support.

(4) For the substitution of toxic and hazardous materials, the lead-free solder research has already been conducted in some units, but there are only lab results, and they are almost not promoted and applied.

\section{PURPOSES AND BASIC PRINCIPLES OF ECO-DESIGN OF WATER HEATER PRODUCTS}

The purpose of water heater product eco-design is to reduce the environmental pollution, and enhance the recyclability rate of water heater products, so as to reduce the adverse environmental impact of water heater products during their entire life cycle, and develop the more ecologic, economic and sustainable water heater products system.

The basic principles for eco-design of water heater products include: the requirements-oriented, advanced technology, scientific methods, environmental-friendly, economic rationality, and abidance by law.

The requirements-oriented principle means that the eco-design shall be oriented by the comprehensive requirements: from the integrated perspective, it is required to take the integrated consideration of the water heater products and the resources integrated utilization requirements of their system; from the process perspective, it is required to comprehensively consider the environmental requirements of water heater products at each stage of their life cycle, especially the environmental requirements during their use, abandonment and processing process; from the performance perspective, it is required to adopt the customized design, avoid the functional waste and enable the water heater products function to properly reflect the system requirements.

The advanced technology principle means that the eco-design shall be based on the applicable technology: In design, it is required to give preference to the advanced design technology; meanwhile, it is required to pursue the enhancement of water heater products environmental index, based on the premise that the technical performance index of the water heater products will not be reduced; the feasible manufacturing technology shall be based on; it is required to adopt the product light weight design; it is also required to adopt the relatively mature environmental technology, reduce the complexity of integrated technology, and carry out the organic integration with the design technology.

The scientific methods principle means that the ecodesign shall be based on the scientific theory: the circular economy theory, industrial ecology theory and life cycle theory shall be based on.

The environmental friendly principle means that the eco-design shall take the environmental protection as the target: in the eco-design of water heater products, it is required to give preference to the environmental friendly advanced design technology. It is required to ensure the safety of water heater products during the processing and manufacturing, use and maintenance, final disposal and 
other processes. When the functions of water heater products are realized, it is also required to pursue the light weight, reuse and recycling, and improve the environmental impact of equipment life cycle, especially the environmental impact during the use, abandonment and processing process. Except for considering the water heater product's own environmental impact, it is also required to attach great importance to the resources integrated utilization performance enhancement of water heater products, and reduce the secondary pollution.

The principle of economic rationality means that the eco-design shall be based on the premise of economic adaptability, and it is required to comprehensively consider the environmental interest of water heater products, including the environmental benefits and costs. Meanwhile, it should also give consideration to the environmental interest of the enterprises, customers and society, and adopt the economic and rational environmental technology.

The principle of abidance by law means that the ecodesign shall take the abidance by law as the criterion, while it is required to abide by the restrictive requirements of national and international regulations, satisfy the technical standards and voluntary agreement, and the market or consumer requirements, development trend and expectation, and reach the social and investor's expectation.

\section{ECO-DESIGN REQUIREMENTS OF WATER HEATER PRODUCTS}

\subsection{Life cycle phase}

The life cycle phase of water heater product considered in the eco-design shall include the product design and development, obtaining, selection and use of raw materials, product manufacturing, package, transportation and distribution, maintenance and repair, product application, and recycling.

\subsection{Environmental factors}

At each phase of the life cycle, it is required to evaluate the following environmental factors: consumption of resources and energy, emission type and quantity of hazardous substances, pollution resulted from the noise, radiation, electromagnetic field and other physical effects, produced waste materials, carbon dioxide emission, use of degradable materials, and recycling (reuse, recycling, energy recovery, and etc.).

The manufacturer shall equip the measuring instrument of energy as per the requirements of GB 17167 [5] and the measuring instrument of water as per the requirements of GB 24789 [6], while the energy efficiency indexes for domestic gas instantaneous water heater and gas fired heating and hot water combi-boilers shall conform to the requirements of GB 20665 [7] and the energy efficiency indexes for electrical storage water heaters shall conform to the requirements of GB 21519 [8]. The electromagnetic compatibility design, general safety requirements, special safety requirements, ecodesign restricted substances testing methods and requirements, product packaging, restricting excessive packaging and recyclability rate of water heater product shall conform to the requirements of GB 4706.1 [9], GB 4706.12 [10], GB/T 26125 [11], GB/T 26572 [12], GB/T 1019 [13], GB/T 31268 [14], GB 4343.1 [15] and QB/T 4505 [16] separately.

\subsection{Eco-design requirements of water heater products}

The requirements of compulsory environmental protection laws and regulations are as follows: the electric safety and product safety, hygiene requirements, energy efficiency standards, noise and electromagnetic compatibility, environmental protection regulations related to the production process, China RoHS2.0, requirements of concentration limits for hazardous substances, safe service life and mandatory abandonment life, and the limit value requirements of recovery rate and reuse rate.

The requirements of non-compulsory environmental protection laws and regulations are as follows: hazardous substances requirements of materials and hazardous substances requirements of packaging. The ecological technical requirements that are not clearly provided by the laws and regulations are as follows: it is required to minimize the quantity of parts and components, minimize the materials type and quantity, maintain the higher standardization and generalization rate, adopt the equal life design principle (if possible), and be easy for maintenance and repair, disassembly, warehousing and distribution.

\section{ECO-DESIGN PROCEDURE OF WATER HEATER PRODUCTS}

The eco-design phase includes the determination of design products and objectives, planning and organization, requirements analysis, preparation of design specification, product design and implementation design, completion of concept design, structure design, detailed design, general scheme design, system design and parts and components design, engineering design and relevant documents.

\subsection{Concept design}

It is required to carry out the generalized product requirements analysis before the concept design of water heater products, and apply the life cycle theory to analyze the manufacturing, use and reuse after abandonment and disposal conditions of the product and parts and components, including the following several aspects: external requirements analysis (user requirements analysis, vendor requirements analysis, supplier requirements analysis, and etc.), internal requirements analysis, and the relevant stakeholder requirements analysis. 
The key points at the concept design phase shall be the balance and optimization of the following target parameters under the precondition that the relevant laws and regulations shall be conformed to: the functions of water heater product, heating method, water storage method, applicable scene, gas water heater (thermal load, thermal efficiency, hot water generating capacity, $\mathrm{CO}$ emission, and NOx emission), solar water heater (daylighting area, daylighting heating efficiency, energy efficiency coefficient, and capacity), and heat pump water heater (heating capacity, rated power, hot water output, maximum power, outlet water temperature, COP energy efficiency ratio), rated capacity, rated power, hot water output rate, vessel pulse pressure, energy efficiency grade, noise, expected lifespan, water heater product specification, and cost.

\subsection{Structure design}

The key points of eco-design at the structure design phase include: the use of environment-friendly renewable materials, improvement of comprehensive utilization performance, water heater sealing requirements, installation compatibility, easy to realize the automatic production, replaceability, maintainability and recyclability of the product, simplification of water heater products and parts and components structure, replaceability and upgrading of core parts, simplification of assembly and disassembly process, easy for the clear separation of non-renewable materials or parts, and the selection and use of refrigerant, foaming agent and coating.

\subsection{Detailed design}

The key points of eco-design at the detailed design phase: the provision of ecological requirements of key working procedure, the provision of comprehensive utilization instructions, environmental protection requirements during the production process, selection of ecological and green environmental protection materials, product freezing resistance, wind resistance and anticorrosion requirements, the water heater sealing requirements, materials aging resistance and water resistance, water leakage, electric leakage and air leakage requirements, health, hygiene and environmental adaptability, dimensional compatibility of alternative products, illustration of assembly and disassembly sequence, illustration of disassembly methods of nonrenewable materials or parts, and the provision of the recycling specification of water heater products and parts and components.

\subsection{General scheme design}

The key points at the general scheme design phase shall be the balance and optimization of the following target parameters, under the precondition that the relevant laws and regulations shall be conformed to: the materials use efficiency, energy efficiency index, noise, standardization and generalization rate, recovery rate, reuse rate, and mean time between failures.

\subsection{System design and parts and components design}

The key points at the system design and parts and components design phase shall be the balance and optimization of the following factors, under the precondition that the relevant laws and regulations shall be conformed to: materials type and quantity (including the selection of renewable materials or recycling materials), recyclability of materials, reusability of materials, concentration limits for toxic and harmful substances in materials, parts and components standardization and generalization rate, and structural detachability.

\subsection{Engineering design}

The key points at the engineering design phase shall be the balance and optimization of the following factors, under the precondition that the relevant laws and regulations shall be conformed to: technical flow, such as: steel plate cleaning, shell coating, foaming technology, processing equipment, testing equipment, tooling, tools and molds, auxiliary materials selection and use level, concentration limits for toxic and harmful substances in auxiliary materials, taking account of environmental safety and personal safety requirements, health (removal and filtering of water quality, bacteria and residual chlorine), environmental protection (selection and use of limescale, foaming agent in materials selection, and environmental impact resulted from the product use process), and energy saving (power and water saving), packaging transportation and user use (experience of appearance, functions, security visualization and interaction), energy consumption, noise and pollutant emission during the manufacturing process, and etc.

\subsection{Preparation of design specification}

It is required to select the appropriate design pattern and formulate the design parameters. It is required to convert the design requirements into the specific specifications, and define the eco-design requirements of the product, for instance, the inclusion of selection of raw materials, functions, costs, supply and distribution, and other measures that conform to the environmental targets, into the product design specification. During the design process, it is required to consider the product life termination (end) handling (reuse, recycling and disposal) requirements, select the appropriate handling methods and estimate the costs.

\subsection{Product design}

The environmental compatible product design tools, such as life cycle assessment (LCA), will be used to optimize the product design. The preliminary design of 
the product shall fully consider the general requirements of the eco-design, implement the design requirements into each composition element of the product, and complete the product sample design. For the detailed design of product sample, it is required to complete the final design scheme of the product after passing through the preliminary design and sample checking and verification, including the detailed product design and manufacturing drawing, engineering construction drawing, technical flow chart, materials selection requirements, handling requirements after the product use, and etc.

\subsection{Implementation design}

It is required to select the appropriate technical equipment, raw materials, and energy, determine the qualified raw materials, and parts and components supplier, and also require the supplier to provide the product eco-design related environmental information, and purchase and install the manufacturing equipment as per the designed technical requirements. It is required to manufacture the product packaging and transportation guidelines consistent with the product environmental requirements, and design the distribution system in coordination with the product environmental requirements. Meanwhile, it is required to select the final disposal methods of the product as per the minimum environmental impact principle. If necessary, it is required to provide the final disposal guideline for the recycling enterprises.

\section{ECO-DESIGN METHODS OF WATER HEATER PRODUCTS}

The eco-design methods of water heater products include the life cycle design method and modularity design method, which may be individually used or used in combination. The methods adopted by the eco-design are including but not limited to these methods.

\subsection{Life cycle design method}

The life cycle design shall aim at the obtaining of raw materials, processing and manufacturing, use and maintenance, use and improvement, final disposal and other phases of life cycle, which adopts the enhancement of the resources utilization efficiency as the target, and the continuous improvement as the means, so as to implement the systematic design. The life cycle design shall consider the requirements analysis, concept design, structure design, detailed design and other general product design process, can be combined with the modularity design, and can also adopt the concurrent design. The use phase is the major link of water heater products life cycle, while it is better to adopt the enhancement of resources utilization efficiency, reduction of number of operation faults, and shortening the downtime of maintenance and repair as the key targets of life cycle design.
The life cycle design process mainly includes the requirements decomposition, design analysis, target identification, technical R\&D, design improvement and life cycle assessment, while the life cycle assessment is associated with the steps of basic process. As shown in Figure 1, it is required to disintegrate the ecological demand into each phase of the life cycle of water heater product, analyze the present eco-design conditions of the product, identify the key design improvement targets, explore the feasible technical realization scheme, conduct the environmental enhancement upon the product design, and implement the life cycle assessment upon the water heater products, so as to support the steps of basic process. For the principles of life cycle assessment, please see GB/T 24040 [17].

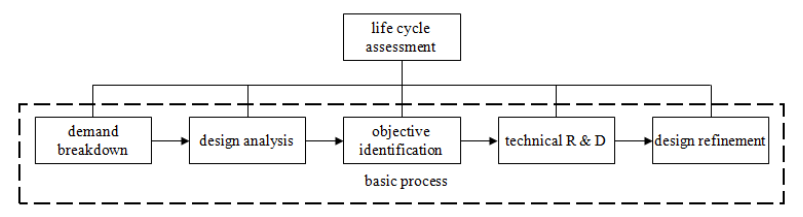

Fig.1, Main process of water heater product life cycle design

The life cycle design is the universal technical methods of water heater product eco-design. Its major ecological functions are as follows: it intends to consider the ecological problems from the life cycle perspective, and enhance the wholeness of eco-design; it intends to identify the key targets and main links, and enhance the pertinence of eco-design; it intends to implement the technical R\&D by centering around the main issues, which facilitates the breakthrough of eco-design key technologies; and it also intends to enhance the ecodesign level at the entire life cycle and its each phase.

\subsection{Modularity design method}

Based on the comprehensive analysis of customer requirements, and as per the systems engineering idea, the modularity design shall disintegrate the water heater product into the serialized, generalized modules, and modules that have the independent functions and are easy for reuse and variance, and obtain the personalized products through the modular synthesis. The modularity design shall be open to the entire water heater product family, fully use the similarity and reusability of the module, and effectively control the diversification of water heater products. The diversification of water heater products includes the external diversification of water heater products that may be felt by the customer, and internal diversification of water heater products that may be felt by the enterprise. The modularity design may be divided into the modularity design of the new water heater products and existing water heater products. The new product modularity design is the innovation of product structure and module, while the existing product modularity design is the rationalization of product structure and module. It may adopt the informatization to support the modularity design.

The process of modularity process mainly includes the module partition, module standardization, product 
modeling, configuration design, variant design and modularity assessment, while the life cycle assessment is relevant to the process of modularity design and the process of customized design, as shown in Figure 2. For the module partition principles of water heater products, please see GB/T 30438 [18]. The module partition, module standardization, and water heater product modeling form the process of product modularity design, while the configuration design and variant design form the process of customized design of the product. It is required to implement the product modularity evaluation, so as to support the steps of the process of modularity design and the process of customized design. The modularity evaluation mainly has the comparison value upon the identical products.

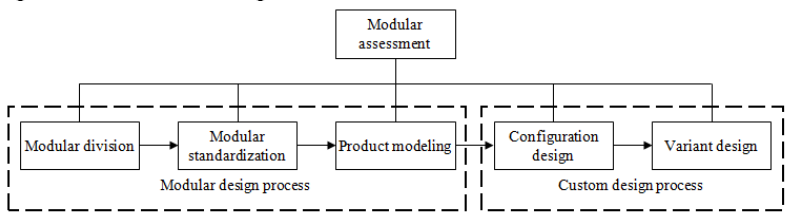

Fig. 2, Main process of modularity design

The modularity design is the generic technical methods of water heater product eco-design. Its major ecological functions are as follows: it intends to support the fast customized design, satisfy the customer's individual requirements, and avoid the waste of manufacturing resources; it intends to enhance the modular production lot, achieve the scale benefit, and make full use of the efficiency of manufacturing resources; it intends to facilitates the use and maintenance, reduce the equipment outage loss, and extend the product life span; it intends to realize the detachability and facilitates the recycling of parts and components; and it also intends to realize the product environmental enhancement through supporting the modularity improvement.

\section{ECO-DESIGN EVALUATION AND IMPROVEMENT OF WATER HEATER PRODUCTS}

The eco-design evaluation of water heater products is a repeated process, which runs through the main process of eco-design, including the preparation of product design specification, product preliminary design, implementation design and other phases. The main evaluation contents include: the appropriateness of design tools, technical feasibility of design scheme, environmental impact assessment, economic assessment, conformity assessment of eco-design targets and principles, and etc. The water heater product eco-design assessment falls into two types, namely, the process assessment and product ecological level assessment. The assessment adopts the comparison with the recent like products, systems or parts and components, while the assessment methods may adopt the radar chart method, LCA method, and etc. If the process assessment cannot satisfy the requirements, it is required to provide the specific improvement measures, and carry out the assessment again, until the assessment index requirements are satisfied. After the completion of ecodesign procedure of water heater product, it is required to carry out the final assessment, while it is recommended that the final assessment shall adopt six indexes for assessment, namely, the energy efficiency index, materials use efficiency, mean time between failures, recovery rate, and recycling rate. Meanwhile, it is recommended to adopt the radar chart method as the assessment method. The water heater manufacturer should establish and implement the environmental management system and hazardous substances management system, while the environmental management system shall conform to the requirements of GB/T 24001 [19].

The design assessment results shall be timely reverted back to the corresponding phase of eco-design, so as to continuously perfect the design tools, design scheme and product improvement plan. During the period from the water heater product launch to the end of life cycle, the product manufacturer shall continuously improve the eco-design of product or repair accessories.

\section{WATER HEATER PRODUCTS INFORMATION PROVISION AND SHARING}

It is required to collect and sort out the laws and regulations related to eco-design of water heater products, and conduct the information communication and exchange along the supply chain direction, enabling the relevant stakeholders to follow the relevant laws and regulations. After the completion of eco-design of water heater product, it is required to share the relevant product eco-design information with the relevant stakeholder.

\section{CONCLUSION}

The eco-design of water heater product is the significant driving force to reduce the consumption of resources and energy, and the emissions of pollutants and greenhouse gas from the source, enhance the technology to develop towards the energy saving, low carbon and green technology direction, and further promote the industrial transformation and upgrading. This paper has analyzed the key environmental impact factors of the water heater product at the aspects of energy consumption, materials consumption, water resources saving, toxic and hazardous substances reduction and substitution. This paper has also analyzed pollutants emission, product abandonment and handling, and consumer-friendliness, and the raw materials obtaining, production and manufacturing, storage, transportation and sales, consumption and use, recycling after abandonment and other phases of life cycle, and has selected the typical indexes at the variable phases to form the assessment index system. Under the precondition that the product can conform to the user's service functions, it is required to ensure the high utilization efficiency, biodegradablity, biosecurity, 
poisonless and harmless property, or low poisonous and low harmful property, and low emissions of resources and energy during the design, production, use, abandonment, disposal, and other whole life cycle process, which is the core idea of water heater ecodesign. Our human beings shall directly face the ecological destruction resulted from the modern scientific and technical development and application, while the ecological product may provide the wiser and more ecological decisions for the users.

\section{Acknowledgement}

This paper is funded by National key research and development plan project "Research on key technology standards of eco-design for consumer electronics and other important products" (2017YFF0207901).

\section{References}

1. Jianfang Zong, Jianhua Chen, Comparative Analysis on Domestic and International Mechanism of Product Ecological Evaluation, China Standardization, 2017, (15): 54-58

2. Jianfang Zong, Jianwei Tian, Dongfeng Guo, Liang Chen, A Study on the Eco-Design of Consumer Electronics; E3S Web of Conference 53, 04003 (2018)

3. GB/T 24256-2009, General Principle and Requirements of Eco-Design for Products

4. GB/T 32161-2015, General Principles for EcoDesign Product Assessment

5. GB 17167, General Principle for Equipping and Managing of the Measuring Instrument of Energy in Organization of Energy Using

6. GB 24789, General Provisions on Equipping and Managing of the Measuring Instrument of Water in Organization of Water Using

7. GB 20665, Minimum Allowable Values of Energy Efficiency and Energy Efficiency Grades for Domestic Gas Instantaneous Water Heater and Gas Fired Heating and Hot Water Combi-Boilers

8. GB 21519, Minimum Allowable Values of Energy Efficiency and Energy Efficiency Grades for Electrical Storage Water Heaters

9. GB 4706.1, Household and Similar Electrical Appliances-Safety Part 1: General Requirements

10. GB 4706.12, Safety of Household and Similar Electrical Appliances-Particular Requirements for Storage Water Heaters

11. GB/T 26125, Electrical and Electronic ProductsDetermination of Six Regulated Substances (Lead, Mercury, Cadmium, Hexavalent Chromium, Polybrominated Biphenyls, Polybrominated Diphenl Ethers) (IEC 62321: 2008, IDT)

12. GB/T 26572, Requirements of Concentration Limits for Certain Restricted Substances in Electrical and Electronic Products
13. GB/T 1019, General Requirements for the Package of Household and Similar Electrical Appliances

14. GB/T 31268, Restricting Excessive Packaging for Commodity-General Rule

15. GB 4343.1, Electromagnetic Compatibility Requirements for Household Appliances, Electric Tools and Similar Apparatus-Part 1: Emission

16. $\mathrm{QB} / \mathrm{T}$ 4505, Requirements of Recycling for Household Water Heater

17. GB/T 24040, Environmental Management-Life Cycle Assessment-Principles and Frameworks

18. GB/T 30438, Principles and Methods for Data Dictionary Technology of Supporting Modularity Design

19. GB/T 24001, Environmental Management Systems - Requirements with Guidance for Use (GB/T 24001-2004, ISO 14001: 2004, IDT) 